\title{
A HISTÓRIA DA MATEMÁTICA ESCOLAR NO GYMNASIO PAES DE CARVALHO (1889-1930): UM OLHAR SOBRE AS FONTES HISTÓRICAS
}

\author{
Iza Helena Travassos Ferraz de Araújo ${ }^{1}$ \\ Universidade Federal do Pará - UFPA \\ izahelena@ufpa.br
}

\begin{abstract}
RESUMO
O objeto de estudo desta pesquisa são as fontes históricas relativas a história da disciplina escolar matemática no Gymnasio Paes de Carvalho, no período de 1889 a 1930, sobre o qual se objetiva analisar de que modo as fontes históricas presentes no arquivo da escola contribuem para o desvelamento da história da matemática escolar nessa instituição. Os fundamentos teórico-metodológicos utilizados foram Goodson (2001) e Chervel (1990), no que se refere a história do currículo e das disciplinas escolares, e Saviani (2004) e Lombardi (2004), no que se refere ao trabalho com as fontes históricas. A pesquisa de campo no arquivo da escola ocorreu de maio a agosto de 2014, período em que foi feita a organização das fontes encontradas e a digitalização dos documentos referentes a dinâmica da escola e a disciplina escolar matemática. A partir da análise destas fontes foi possível fazer considerações acerca de algumas dimensões da matemática escolar, principalmente, no que se refere aos professores que ensinavam matemática no ginásio, pois revelam a cotidianidade das relações interpessoais e interinstitucionais dos atores da escola.

Palavras-Chave: Matemática Escolar; Currículo; Gymnasio Paes de Caravalho; Fontes Históricas
\end{abstract}

\section{THE HISTORY OF SCHOOL MATHEMATICS AT GYMNASIO PAES DE CARAVALHO (1889-1930): A LOOK ON THE HISTORICAL SOURCES}

\begin{abstract}
The object of study of this research are the historical sources for the history of school discipline mathematics at Gymansio Paes de Carvalho, in the period 1889 to 1930, on which the objetctive is to examine how historical sources present in the school file contribute to the unveiling of the history of school mathematics that institution. The theoretical and methodological foundations were used Goodson (2001) and Chervel (1990), as regard the history of the curriculum and of school subjects, and Saviani (2004) and Lombardi (2004), with regard to working with the historical sources. The field research in the school file occurred from May to August 2014, during which the organization was made of the sources found and the digitization of documents relating to the dynamics of school and school discipline mathematics. From the analysis of these sources it was possible to make considerations about some dimensions of school methematics, especially with regard to teachers who taught mathematics at the gym, because they reveal the daily life of interpersonal and inter-institutional relations of school actors.

Keywords: School Mathematics; Curriculum; Gymnasio Paes de Caravalho; Historical Sources
\end{abstract}




\section{Introdução}

Neste artigo objetivo apresentar resultados parciais de minha pesquisa de doutorado sobre a história da disciplina escolar matemática no Gymnasio Paes de Carvalho (18891930), relativos ao trabalho com as fontes históricas encontradas no arquivo da escola. O estudo da história da disciplina escolar matemática se situa no campo de estudos da História da Disciplinas Escolares (HDE), área de estudo que tem contribuído para o desvelamento da História do Currículo que, por sua vez, "consiste dos estudos históricos que têm por objeto o currículo enquanto conjunto de conhecimentos selecionados e enquanto conjunto de práticas e rituais associados ao processo de transmissão e construção desses conhecimentos" (LOPES, 1998, p. 60). Ao abordar a história da matemática escolar, devemos recorrer aos pressupostos teóricos da história do currículo, pois nos ajudarão a compreender os aspectos sociais, políticos, didáticos e de conhecimento referente a esta disciplina, além dos aspectos do controle e do funcionamento da escola e da sala de aula (GOODSON, 2001) Porém, segundo Lopes (1998), é importante considerar que a história do currículo compreende a história do pensamento curricular, a história das disciplinas e os estudos de caso, tais como a história de um curso ou de uma instituição escolar.

A seleção de um única instituição para o estudo da história da disciplina escolar matemática surgiu da necessidade de analisar os macroprocessos ao nível do particular e conhecer como a escola reflete e/ou refrata as questões de ordens sociais, politicas e culturais inerentes ao currículo dessa disciplina em um determinado período histórico. Isso se justifica porque o currículo, a estruturação, as finalidades e o funcionamento da escola só podem ser compreendidos se vistos como resultantes de questões internas e externas à escola. A delimitação temporal nos permite conhecer os valores e as crenças desse período histórico e compreender porque determinadas formas de conhecimento matemático alcançaram especial status no currículo, enquanto outros conhecimentos foram excluídos. É importante também para vermos que "o conhecimento corporificado no currículo não é algo fixo, e sim um artefato social, histórico, sujeito a mudanças e flutuações. O currículo está em constante fluxo e flutuações" (SILVA, 2013, p. 10).

O lapso temporal de 1889 a 1930 consiste no período de transição do final do século XIX e no início do século XX, que foi marcado pela transição da monarquia para a república, pelo fim da escravidão, pelo início da industrialização e pelo advento do trabalho assalariado. Esse período, denominado como Primeira República, é marcado então por um conjunto de leis e reformas para a instrução secundária brasileira, marcadas por conflitos e interesses de formação para emergência e manutenção de uma (nova) elite e de uma nova sociedade. Foi nesse contexto também que a matemática escolar brasileira passou por grandes transformações, dentre as quais, a fusão da Aritmética, Álgebra e Geometria (que inclui a Trigonometria) em uma única disciplina escolar, a Matemática, que se dá "em meio a um período revolucionário e expressa uma mudança de paradigma das influências culturais" (VALENTE, 2004, p. 171). Essas transformações curriculares ocorreram nos campos epistemológicos e didáticos da disciplina, com implicações nos processos de ensino e aprendizagem e na elevação do status da matemática enquanto componente curricular do ensino secundário brasileiro

Considerando estes aspectos, o objeto de estudo desta investigação são as fontes históricas relativas a disciplina escolar matemática no Gymnasio Paes de Carvalho, no período de 1889 a 1930, e o objetivo é analisar de que modo as fontes históricas presentes no arquivo da escola contribuem para o desvelamento da história da matemática escolar nessa instituição.

O texto resulta de uma pesquisa histórica, relativa à história da disciplina escolar 
matemática, e do trabalho com as fontes históricas de uma instituição escolar pública de ensino secundário da Amazônia. A investigação teve início em setembro de 2013, porém, o trabalho com as fontes históricas encontradas no arquivo da escola começou em maio de 2014. Na escrita, em primeiro lugar, apresento o aporte teórico para o estudo da história do currículo e das disciplinas escolares, com destaque para contribuições das instituições escolares nesse campo de estudo, seguido por um breve histórico do Gymnasio Paes de Carvalho, instituição locus da pesquisa. Por conseguinte, proponho um olhar sobre as fontes históricas, seguido pela descrição do modo como realizei a seleção, levantamento, organização e análise das fontes encontradas no arquivo da escola, bem como, dos resultados obtidos. Finalizo com algumas considerações acerca do trabalho com as fontes históricas presentes nas instituições escolares no processo de investigação sobre a história das disciplinas escolares.

\section{A História do Currículo e das Disciplinas Escolares}

O conceito lato de currículo que assumo neste texto é que currículo é conhecimento que se materializa num projeto de formação que se situa num espaço e decorre num tempo concreto (PACHECO, 2014). Por ser uma construção social, o currículo está intimamente ligado a um projeto de sociedade e é marcado por conflitos, em particular, quando tratamos da eleição dos conhecimentos que irão compor o currículo escolar. Segundo Goodson (2001), o conhecimento escolar e currículo são realizados pedagogicamente num contexto social e se materializam na escola por meio das disciplinas escolares. Para este autor,

Se os vocábulos "classe" e "currículo" entraram no discurso educacional, quando a escolarização foi transformada numa atividade de massas, as expressões "sistema de salas de aula" e "disciplina escolar" foram ligadas numa fase em que essa atividade se tornou num sistema subsidiado pelo Estado. E, não obstante as muitas maneiras alternativas de conceptualizar e organizar o currículo, a convenção de disciplina retém a sua supremacia. Na era moderna, lidamos, essencialmente, com um currículo enquanto disciplina (ibidem, p. 66).

Sobre as disciplinas escolares, Goodson (2001) nos apresenta três conclusões. A primeira conclusão é que "as disciplinas não são entidades monolíticas mas, antes, amálgamas flutuantes de subgrupos e de tradições que, através da contestação e do compromisso, influenciam o rumo das mudanças" (GOODSON, 2001, p.101). Por conseguinte, interpreto que as disciplinas não são um conjunto rígido e indivisível, mas são heterogêneas, de diferentes classes e qualidades, resultantes de conflitos e acordos, que têm influências e consequências na sociedade.

A segunda conclusão é que "o processo de conquista da condição de disciplinas escolar revela a evolução da comunidade disciplinar, desde a promoção de propósitos pedagógicos e utilitários até a definição da disciplina como 'acadêmica', com ligações ao especialista universitário" (ibidem, p. 101). Visto que há um processo de conquista, com efeito existem conflitos entre pessoas com interesses na transformação de um determinado conhecimento em conhecimento escolar. Esta condição é alcançada quando esse conhecimento se torna mais abstrato e, consequentemente, mais próximo do conhecimento acadêmico.

A terceira conclusão é mais complexa, pois afirma que "o debate sobre o currículo pode ser interpretado em termos de conflitos entre as disciplinas a propósito de status, de recursos e de territórios" (ibidem, p. 101). Esta conclusão está intrinsecamente ligada as 
tensões existentes no campo do currículo e envolve a complexidade que constitui os textos e os processos curriculares, questões de ordem social, epistemológicas e de poder.

As outras dimensões do currículo que desejo destacar são tempo e espaço. Pacheco (2014, p. 48) nos apresenta uma forma de lidar com essas duas grandezas, afirmando que "no processo de escolarização, sobretudo a partir da institucionalização da educação pública, os conteúdos escolares têm sido sujeitos a ruturas e mudanças em função de contextos diversos". O autor utiliza a noção tempo/espaço curricular para se referir "a esses contextos, de natureza social, económica, política, cultural e ideológica, que, de modo direto ou indireto, têm influências na construção pública da educação" (ibidem, p. 48). Dessa forma, para que possamos compreender as transformações curriculares, é necessário situar o conhecimento escolar, a escola e os(as) educadores(as), ou seja, problematizar o aquilo que para os homens e as mulheres de um determinado período histórico é inquestionável (APPLE, 1999).

Mais especificamente sobre o campo da História das Disciplinas Escolares, Chervel (1990) destaca a produção do conhecimento escolar pela própria escola, segundo esse autor, um investigador se depara com três problemas generalizados, o primeiro relacionado a sua gênese, o segundo em relação à sua função e o terceiro ao de seu funcionamento, com destaque para este último sobre o qual afirma que "Longe de ligar a história da escola ou do sistema escolar às categorias externas, ela se dedica a encontrar na própria escola o princípio de uma investigação e de uma descrição histórica específica" (CHERVEL, 1990, p. 184)

Por conseguinte, a instituição escolar se torna fundamental no estudo da história das disciplinas escolares pois

O estudo dessas leva a pôr em evidência o caráter eminentemente criativo do sistema escolar, e portanto a classificar no estatuto dos acessórios a imagem de uma escola encerrada na passividade, de uma escola receptáculo dos sub-produtos culturais da sociedade. Porque são criações espontâneas e originais do sistema escolar é que as disciplinas merecem um interesse todo particular. E porque o sistema escolar é detentor de um poder criativo insuficientemente valorizado até aqui é que ele desempenha na sociedade um papel o qual não se percebeu que era duplo: de fato ele forma não somente os indivíduos, mas também uma cultura que vem por sua vez penetrar, moldar, modificar a cultura da sociedade global (ibidem, p. 184).

Um dos problemas mais complexos com o qual nos defrontamos na história do ensino, é o problema da identificação, classificação e organização dos objetivos ou finalidades da escola, pois estas sofrem, em cada época, mudanças de toda ordem, com implicações em sua função educativa. Nesse sentido, ganham destaque as disciplinas escolares que estão no centro da relação entre educação e instrução, cuja função "consiste em cada caso em colocar um conteúdo de instrução a serviço de uma finalidade educativa" (ibidem, p. 188).

As finalidades educativas devem ser analisadas sob dois olhares, um olhar sobre o que o autor denomina como finalidades objetivo que estão contidas nos documentos, tais como, textos oficiais programáticos, discursos políticos, leis, ordens, decretos, entre outros, ou seja, no currículo prescrito, o currículo sancionado pelo Estado e que é adotado pela estrutura organizacional escolar. E outro olhar sobre as finalidades reais, que não estão obrigatoriamente escritas nos textos oficiais, mas que fazem parte do currículo real ou currículo em ação, que acontece na prática diária da escola, bem como do currículo oculto, 
que abrange os processos e os efeitos que, não estando previstos no currículo prescrito, fazem parte da experiência escolar (CHERVEL, 1990; PACHECO, 2001). Dessa forma, novos ensinos são introduzidos sem terem sido formulados, influenciados pelos agentes que constituem a escola, tais como, professores, alunos, gestores.

Chervel (1990) destaca que é imperativo ao historiador das disciplinas fazer a distinção entre essas distintas finalidades, uma vez que as finalidades impostas à escola se materializam no ensino escolar, que é a parte da disciplina que provoca a aculturação conveniente. Para esse autor, descrever a história da disciplina não deveria se limitar a apresentar a história dos conteúdos, que se constituem apenas um meio para se alcançar um fim, é necessário o estudo do ensino efetivado que, por sua vez, requer um trabalho com as fontes históricas presentes nas escolas, pois

Cada época produziu sobre sua escola, sobre suas redes educacionais, sobre os problemas pedagógicos, uma literatura frequentemente abundante: relatórios de inspeção, projetos de reforma, artigos ou manuais de didática, prefácios de manuais, polêmicas diversas, relatórios de presidentes de bancas, debates parlamentares, etc. É essa literatura que, ao menos tanto quanto os programas oficiais, esclarece os mestres sobre sua função e que dá hoje a chave do problema (ibidem, p. 190-191).

Portanto, a eleição do Gymnasio Paes de Carvalho para o estudo da história da disciplina matemática nos permite, além de investigar o seu ensino efetivado, elucidar a complexa relação entre o processo de instrução e a função educativa da escola. Por conseguinte, suas fontes históricas se tornam a chave, por um lado, para escrever uma história sobre o ensino dessa disciplina em determinado espaço/tempo e, por outro, compreender as redes interinstitucionais que envolvem a constituição da própria disciplina como parte do currículo da escola, de acordo com seu conjunto de finalidades. Por conseguinte, por esta instituição escolar ser uma das mais antigas do Brasil e da Amazônia, o estudo de seu currículo por meio das fontes históricas do arquivo da escola, traz importantes contribuições à História da Educação.

\section{O Gymnasio Paes de Carvalho e a Instrução Secundária Paraense na Primeira República}

O Gymnasio Paes de Carvalho, atual Escola Estadual de Ensino Médio "Paes de Carvalho", localizado na Praça Saldanha Marinha, no bairro do Comércio de Belém do Pará, Brasil, iniciou sua história a partir da Lei $n^{\circ}$ 97, de 28 de junho de 1841, que regulamentou a instrução primária e secundária da Província do Pará e criou o Liceu Paraense, primeira instituição de instrução secundária do Estado. Sua criação ocorreu no período em que coube aos governos das províncias a responsabilidade sobre a instrução pública e estabelecimentos próprios para promovê-las, surgindo em consequência os primeiros liceus provinciais, localizados nas suas respectivas capitais, tais como, $\mathrm{O}$ Ateneu, do Rio Grande do Norte em 1835 e os Liceus da Bahia e da Paraíba, ambos em 1836 e o Imperial Colégio Pedro II em 1837, na Corte (ROCHA, 1994).

Em seu primeiro currículo, o ensino secundário era constituído por dois cursos, o de Humanidades e Comércio, com duração de cinco e dois anos respectivamente, com as seguintes cadeiras: "Língua Latina; Língua Francesa; Aritmética, Álgebra e Geometria; Filosofia Racional e Moral; História Universal, Geografia Antiga e Moderna e História do Brasil; Retórica, crítica, Gramática Universal e Poética; Escrituração Mercantil e Contabilidade; Língua Inglesa" (FRANÇA, 1997, p. 120-121). Um currículo 
essencialmente universalista e humanístico com propósito de servir de acesso ao ensino superior, porém

os alunos formados pelos Liceus provinciais, que almejavam cursar cursos superiores, eram obrigados a prestar os Exames Prepartórios, ou se transferir para o Colégio Pedro II, durante a realização do curso, de modo a concluírem seus estudos e usufruírem do direito automático de matrícula nos cursos superiores (ibidem, p. 85)

Entretanto, em 11 de outubro de 1889 a lei $\mathrm{n}^{\circ} .1 .408$, que estabelece uma reforma da instrução pública na Província do Grão-Pará, cria as cadeiras das matérias exigidas como preparatórios para as escolas superiores do Império no Liceu. Esse é um marco importante para essa instituição, uma vez que esse é o passo inicial para a reforma do currículo, com implicações nos programas de ensino, na organização das matérias e nas certificações emitidas. No início do período republicano essa reforma é ratificada pelo decreto $\mathrm{n}^{\circ} .149$ de 7 de maio de 1890, que estabelece que "O ensino secundário é dado: no Lyceu Paraense em um curso de preparatórios exigidos para as matrículas nos cursos superiores da República". Porém, em 1891, esse ensino novamente é alterado e o decreto $\mathrm{n}^{\mathrm{o}} .372$ de 13 de julho de 1891 estabelece que "o ensino secundário será dado no Lyceu Paraense, em um curso de Sciencias e Lettras, organizado de acordo com as exigências do Governo Federal, para matrícula nos cursos superiores da República".

Segundo Chaquiam, Gaspar e Borges (2010), o acontecimento mais importante na vida do Liceu foi a equiparação em relação ao Ginásio Nacional, atual Colégio Pedro II, no Rio de Janeiro, pelo decreto de $\mathrm{n}^{\circ}$. 1.121 de 01 de novembro de 1892, pois não só cresceu em termos de matrícula, como "pôde gozar de inúmeras reformas que atendiam diretamente aos alunos do mesmo e o credenciamento desta instituição como ascensão da instrução dos paraenses" (CHANQUAM; GASPAR; BORGES, 2010, p. 6).

Foi em meio a esse período de transição de Império para a República que o governador do Estado Dr. Augusto Montenegro estabeleceu, pelo decreto n ${ }^{\circ} .959$ de 9 de fevereiro de 1901, que o Liceu Paraense passaria denominar-se Gymnasio Paes de Carvalho, em homenagem ao ex-governador do Estado Dr. José Paes de Carvalho. Não foi apenas uma mudança de nomenclatura, mas também uma mudança de status, o Liceu, que no final do Império estava em decadência, no início da República, inicia sua ascensão e o período áureo que marcou sua história.

No Brasil, apesar dos ideais republicanos e da necessidade de ampliar a oferta da educação para a população brasileira, a implementação dos ginásios era voltada apenas para uma parte desta população de onde deveria surgir a elite intelectual. Além disso, os ginásios possibilitavam a passagem para o ensino superior, se tornando lugar de seleção dos melhores, ou seja, dos aristocratas (ABUD, 1993). Segundo Abud (1993), os exemplos do Ginásio Nacional no Rio de Janeiro e do Ginásio da Capital em São Paulo mostram que a origem do ginásio no Brasil está relacionada com a aristocratização do ensino, ou melhor, para o ensino da elite brasileira do período de transição do Império para a República.

Com o Gymnasio Paes de Carvalho não foi diferente, locus de formação das elites do Estado do Pará, era equiparado ao Ginásio Nacional e certificava seus alunos como Bacharéis em Ciências e Letras. Segundo Ribeiro (2013, p. 55),

A equiparação revolucionou o currículo praticado à época, já que previa a adoção do mesmo plano de estudos do Pedro II, os exames de admissão para alunos, concurso público para admissão de professores e, 
principalmente, a emissão de diplomas reconhecidos para matrícula nos cursos superiores. Tudo isso era realizado sob a inspeção, a fiscalização e o acompanhamento dos inspetores do Governo Federal.

Além disso,

É a partir deste momento, que o Gynásio Paraense que até então esteve distante dos interesses dos estudantes locais, passa a ser alvo de interesse e de disputa por matrícula, já que anteriormente os alunos e alunas preferiam as poucas escolas particulares reconhecidas por suas famílias pela rigorosa disciplina e por garantir acesso às faculdades; ou, então, buscavam formação secundária em colégios situados fora do estado e que garantissem a matrícula nos cursos superiores. A partir deste momento, além da disputa por matrícula, há a busca pelo status de ser professor ou aluno do Gynásio, que equiparado ao Pedro II, passa a ser referência local e nacional em qualidade de ensino. (ibidem, p. 65-66)

Foi nele que estudaram governadores, ministros, prefeitos de Belém, vicegovernadores, vereadores, deputados, secretários de Estado, presidentes da Assembleias Legislativa, presidentes de Tribunal de Justiça, dentre outros vultos políticos, artísticos e culturais da história paraense. Essa extensa lista de ex-alunos, combinada com a lista de ex-professores, contribuiu para que manter viva, até os dias atuais, a tradição da instituição que, a partir de 1942, passou a ser denominada como Colégio Estadual Paes de Carvalho, o CEPC, nome pelo qual é conhecido até os dias de hoje.

O processo de equiparação, como vimos, foi um marco para a instituição, principalmente no que se refere a constituição de seu currículo. O processo de instrução era bem determinado pelo Ginásio Nacional, que elaborava os programas de ensino, determinava os modos de realização dos exames e certificação, bem como, realizava a inspeção. Porém, as finalidades educativas da escola estavam ligadas ao projeto de sociedade do Estado do Pará, em particular, de sua capital Belém, que vivia os tempos áureos do ciclo da borracha, o que certamente trouxe implicações na sua estrutura física, na estruturação de seu corpo docente e nas suas relações institucionais.

Em relação a disciplina escolar matemática, é possível verificar que seus ramos, a Aritmética, Álgebra e Geometria estiveram presentes desde sua fundação, no primeiro currículo do curso de Humanidades. Entretanto, é necessário um estudo sobre o modo como o processo de equiparação e as transformações epistêmico-didáticas ocorridas nessa disciplina no âmbito nacional, reverberaram na constituição de seu currículo na escola. Os documentos oficiais e programas de ensino contribuem para uma elucidação dessa questão, porém, as fontes históricas presentes na escola, tais como, ofícios, relatórios e atas, é que nos permitem, de fato, um estudo do ensino efetivado dessa disciplina.

\section{Um olhar sobre as fontes históricas}

\section{Algumas considerações}

O trabalho com as fontes históricas é imperativo e desafiador e, assim com a ciência da história inexiste sem um objeto de investigação, não é possível a compreensão de um objeto de investigação sem as fontes que, por sua vez, fundamentam e embasam a própria pesquisa histórica (LOMBARDI, 2004). Dessa forma, vale uma reflexão sobre o 
conceito, a busca, a seleção, o levantamento, a organização e o tratamento das fontes históricas.

Tomarei como ponto de partida para as reflexões sobre o conceito de fontes o texto "Breves considerações sobre fontes para a História da Educação" de Saviani (2004), no qual, ao iniciar sua fala sobre o termo, parte do conceito de fonte por meio das conotações atribuídas à palavra e inicia uma analogia dos sentidos da palavra com o contexto das fontes para a história da educação:

As fontes estão na origem, constituem o ponto de partida, a base, o ponto de apoio da construção historiográfica que é a reconstrução, no plano do conhecimento, do objeto histórico estudado. Assim, as fontes históricas não são a fonte da história, ou seja, não é delas que brota e flui a história. Elas, enquanto registros, enquanto testemunhos dos atos históricos são a fonte do nosso conhecimento histórico, isto é, é delas que brota, é nelas que se apoia o conhecimento que produzimos a respeito da história (ibidem, p. 5-6).

Lombardi (2004) ressalta que as fontes históricas resultam das ações do homem, mesmo que tenham sido produzidas sem a intencionalidade de deixar registros, são testemunhos dos homens e de suas relações com outros homens, com o mundo circundantes e com a natureza. Por outro lado, Le Goff (2000, p. 103) afirma que "a memória coletiva e a sua forma científica, a história, aplicam-se a dois tipos de materiais: os documentos e os monumentos" (grifos do autor). Segundo este autor, o monumentos são caracterizados pela capacidade de perpetuar as sociedades históricas que somente numa parcela mínima são testemunhos escrito, enquanto que os documentos, afirmam-se como um testemunho essencialmente escrito e parece que possuem a objetividade que se contrapõe à intencionalidade dos monumentos (ibidem, 2000). Entretanto, Lombardi (2004, p.156) nos alerta que

Nem sempre os monumentos ou os documentos afloram de forma que se tornem conhecidos e utilizáveis pelo homem para entender como viveram e vivem os próprios homens. Assim, não resta outra alternativa ao historiador: é preciso definir claramente o que deseja estudar, recortando e delimitando o objeto de investigação; feita a(s) escolha(s), é necessário buscar todo tipo de fonte que ajude a reconstruir (em pensamento) o objeto de investigação delimitado.

Retomando a analogia proposta por Saviani (2004), temos que para além do caráter de origem das fontes, o aspecto da natural da fonte é semelhante ao seu aspecto histórico no caráter da inesgotabilidade, uma vez que "sempre que a elas retornamos, tendemos a descobrir novos elementos, novos significados, novas informações que nos tinham escapado por ocasião das incursões anteriores" (ibidem, p. 6). Ou seja, ao revisitar as fontes, o pesquisador pode lançar novos olhares sobre as mesmas, a partir dos quais surgem novas formas de saber e de compreender a própria história,

A ampliação da noção de fonte foi também acompanhada por uma guinada na ótica do pesquisador, que passou a considerar documentos históricos dignos de conservação, transmissão e estudo, não somente aqueles referentes à vida dos grandes homens, dos heróis, dos grandes acontecimentos, das instituições - como na perspectiva positivista. Com Engels e Marx, e depois com Febvre e Bloch, aprendemos que a vida de 
todos os homens, todas as formas de relações, todos os agrupamentos e classes sociais constituem objetos de estudo que interessam ao investigador (LOMBARDI, 2004, p. 157).

Além disso, a seleção, organização e interpretação das suas fontes estão em conformidade com as opções teórico-metodológicas do pesquisador.

Trata-se, então, de uma escolha, ou melhor, de uma série de escolhas que o pesquisador faz na fase do planejamento e também da execução de sua pesquisa. Ele seleciona as suas fontes e, para fazê-lo, deve considerar como fatores decisivos, a pertinência ao tema estudado e a acessibilidade das fontes. Esse material torna, assim, para o pesquisador, o conjunto de suas fontes de pesquisa (TOLEDO; GIMENEZ, 2009, p. 110).

Neste sentido, é importante mencionar os tipos de fontes com as quais o pesquisador se depara que, segundo Toledo e Gimenez (2009), podem ser classificadas em fontes primárias e secundárias. As fontes primárias possuem uma relação direta com $o$ tema estudado e remetem diretamente a problemática da investigação, enquanto que e fontes secundárias, transmitem os fatos de maneira indireta e também fornecem um lastro de informações (datas e fatos), que subsidiam a análise do pesquisador. Os autores também destacam a literatura de apoio que permite ao pesquisador "estabelecer o diálogo necessário com a produção acadêmica relativa ao tema que é pesquisado, principalmente, a mais recente e mais especializada" (ibidem, p. 111).

Lombardi (2004) corrobora com estes autores quando afirma que:

as fontes de pesquisa constituem as próprias produções históricas, em diversos formatos iniciais de produção e de divulgação, entre os quais: relatórios de pesquisa, monografias, dissertações e teses, livros, artigos científicos, anais de eventos científicos, arquivos digitais disponíveis na internet (p. 159)

Por conseguinte, "uma pesquisa histórica terá, então, como tarefa, após a delimitação do assunto a ser pesquisado, eleger as fontes primárias, relacionar as fontes secundárias e a literatura de apoio para nelas sustentar a investigação" (TOLEDO; GIMENEZ, 2009, p. 111). Porém, o pesquisador do campo da história da educação vivencia algumas dificuldades oriundas do "péssimo estado de conservação de uma boa parte do acervo, fruto do descaso dos poderes públicos para com a memória e o patrimônio cultural" (SILVA, 2009, p. 160), principalmente quando se investiga um período cronologicamente tão distante e "das 'lacunas' frequentemente encontradas nas séries documentais" (ibidem, p. 160) que podem prejudicar os modos de concatenar a organização espaço-temporal.

Os desafios do trabalho com as fontes históricas explicitados anteriormente nos alertam para os cuidados na busca, seleção, levantamento, organização e tratamento das fontes históricas. A eleição do objeto de estudo aliada a literatura de apoio, se constituem o primeiro passo na busca e seleção das fontes. $\mathrm{O}$ processo de levantamento deve levar em consideração a classificação das fontes em primárias e secundárias e requer modos específicos de manuseio dos documentos, incluindo o processo de digitalização. Durante a organização e tratamento das fontes, é dever do historiador fazer

a crítica do documento - qualquer que ele seja - enquanto monumento. $\mathrm{O}$ documento não é uma mercadoria invendida do passado, é um produto da 
sociedade que o fabricou segundo as relações de força que nele detinham o poder. Só a análise do documento enquanto documento permite à memória colectiva recuperá-lo a ao historiador usá-lo cientificamente, isto é, com pleno conhecimento de causa (LE GOFF, 2000, p. 112).

Esse é o ponto crucial da pesquisa e requer, além da imersão do pesquisador no tema/projeto, o estabelecimento de relações entre as fontes, a busca pelo que Garcez (2009) denomina como "elo perdido" na construção da historiográfica da educação.

\section{O método de trabalho}

O trabalho com as fontes iniciaram com uma pesquisa sobre as produções acadêmicas relacionadas ao tema da tese, mais especificamente, sobre a história da instituição Gymnasio Paes de Carvalho, dentre as quais destaco Bassalo (1995), França (1997), Rêgo (2002) e Ribeiro (2013).

Bassalo (1995), em seu artigo "O ensino da Física em Belém do Pará" nos apresenta a história do ensino da física em Belém e traz algumas contribuições acerca da história das instituições de ensino da capital, sua pesquisa e textos apresentados em seu blog, abordam a história do ensino da física e da matemática, com uma exposição de fatos, nomes e datas, alguns desses fatos relacionados à sua própria história pessoal, que nos ajudam a situar a instituição pesquisada no cenário educaional paraense. França (1997), em sua dissertação de mestrado intitulada "Raízes Históricas do Ensino Secundário Público na Província do Grão-Pará: o Liceu Paraense - 1840-1889” apresenta a história do Liceu Paraense no contexto histórico amazônico-paraense, destacando a relação dessa instituição com o político, econômico e social, além de expor informações sobre as leis, decretos e currículo relativos a escola. Ambas as fontes trouxeram contribuições para minha pesquisa de doutorado, no sentido de delimitação do tema e construção do objeto de estudo.

Rêgo (2002), em seu livro "Subsídios para a história do Colégio Estadual Paes de Carvalho", registra os aspectos históricos, sociais e políticos dessa instituição, além de transcrever documentos originais, relatos de ex-alunos e reproduzir fotos/imagens de ruas, eventos e da estrutura física da escola. O autor, já falecido, era ex-aluno e ex-professor do CEPC, e sua escrita é carregada de admiração e respeito a instituição e aos que lá passaram, e também se caracteriza coo uma grande homenagem aos professores e a própria escola. Ribeiro (2013), por sua vez, faz uma análise crítica no que se refere a tradição do CEPC em sua tese "A tradução da tradição em práticas curriculares no Colégio Estadual Paes de Carvalho", uma pesquisa que contempla uma realidade mais atual do CEPC e que tem foco nas práticas curriculares de tradução da tradição dessa instituição. Essas fontes me possibilitaram, inicialmente, ter acesso a algumas fontes próprias da escola e, por conseguinte, levantar o problema de pesquisa.

A partir dessas produções, incicei a busca por documentos relativos ao período histórico delimitado no Arquivo Público do Estado do Pará, onde fiz o curso de manuseio e digitalização de documentos históricos, mas não encontrei documentos relativos ao período selecionado, sendo informada de que os mesmos estariam presentes no próprio arquivo da escola; no setor de Obras Raras da Biblioteca da Fundação Cultural Tancredo Neves CENTUR, onde obtive a cópia digitalizada dos "Programmas de Ensino" do ginásio, do período de 1913 a 1929, e da tese "Os incomensuráveis e o methodo geometrico na variação das funções", trabalho apresentado à congregação do ginásio por Antônio Travassos da Rosa, candidato ao provimento effectivo da $2^{a}$ cadeira de Mathematica, em 1921; no setor de Obras Raras da Biblioteca da Universidade Federal do Pará pude digitalizar a "Polyanthea commemorativa da sua fundação e inauguração", documento que 
apresenta um relato sobre a instrução pública secundária no Pará, no período de 1841 a 1910, e o relatório intitulado "A Instrucção Pública do Estado do Pará de 1890", escrito por José Veríssimo, o então diretor de instrução pública do Estado.

Entretanto, essas fontes, embora importantes, não eram suficientes para o desvelamento da história da matemática escolar nessa instituição, eram necessários documentos que tratassem mais diretamente do currículo prescrito e realizado na escola. Embora tivesse obtido os programas de ensino do ginásio, os mesmos estavam incompletos, e a listagem dos conteúdos a serem ensinados era insuficiente para escrever uma história dessa disciplina na escola. Se tornava necessário obter outras fontes que me permitessem fazer um estudo do ensino efetivado, os arquivos escolares propriamente ditos, pois

As instituições de ensino, certamente, possuem sua ata de instalação, primeiros estatutos e regimento interno, autorizações legais necessárias para seu devido funcionamento, cadernetas escolares dos professores, registros de eventos (exposições, seminários, palestras), fotografias várias, inclusive de formatura, alunos em sala de aula etc. E ainda o material de secretaria como matrícula de alunos, notas, os históricos escolares dos alunos, registro de professores que deram aulas no estabelecimento, disciplinas que lecionaram, programas de cursos, entre outros. É um material que precisa ser conservado por longos anos, em razão de seu valor legal, para atender a demanda de fornecimento de certificados para os alunos, ou de tempo de serviço para para professores e funcionários. Alguns estabelecimentos de ensino são bastante cuidadosos com seu arquivo institucional, embora a maior parte deles, muitas vezes, não se preocupe muito com a sua adequada organização e preservação (NUNES; MATOS; CABRAL, 2009, p. 57)

O início da pesquisa empírica no arquivo do escola foi em maio de 2014, quando eu e meu companheiro de pesquisa in loco, o mestrando Maradei dos Santos, conseguimos adentrar no arquivo da escola por meio de ofício obtido junto ao Secretário Adjunto da Secretaria de Educação do Estado do Pará. Fomos recebidos pelo secretário da escola, o Sr. Afonso, que nos mostrou o arquivo da escola que fica em anexo a secretaria e contém arquivos antigos e novos em um mesmo espaço. Esse foi o momento com o qual nos deparamos com o estado de abandono das fontes históricas ali existentes, pois não há uma adequada organização e preservação dos arquivos, que estão pouco a pouco se desfazendo.

A primeira etapa foi tirar os arquivos dos armários e fazer uma limpeza superficial. Nessa retirada, foi realizada uma classificação dos arquivos por décadas 1990, 1980, 1970, 1960, 1950, 1940 e 1930, os arquivos anteriores a década de 1930. Foram colocados nas estantes os arquivos referentes a ao período de 1940 a 1990, com placas de papel indicando as décadas. Ainda encontramos alguns arquivos das décadas de 1880 e 1890 e alguns dicionários e enciclopédias em francês.

Com a impossibilidade de classificar todo o material encontrado, iniciei uma pesquisa exploratória sobre os arquivos encontrados que estavam compreendidos entre as décadas de 1890 e 1930, dessa vez, nãos os classificando por datas, mas por tipos de livros/arquivos. Procurava, por um lado, encontrar fontes históricas que me ajudassem a compreender a dinâmica da escola no período delimitado, por outro, tudo que estivesse relacionado a disciplina matemática. Simultaneamente a pesquisa exploratória, inciei o processo de digitalização dos documentos e de registro das visitas, por meio de anotações em um caderno que se tornou um "diário de pesquisa". Os documentos digitalizados foram 
classificados em pastas virtuais, denomiandas de "GPC" (inicias do nome da escola), que além de numeradas, são identificadas por datas das visitas. Obtive um total de 12 pastas, referentes as 12 visitas realizadas, conforme o quadro 1 .

Quadro 1: Organização das fontes por datas das visitas

\begin{tabular}{|c|c|}
\hline Pastas & Data da visita \\
\hline GPC1 & $28 / 05 / 2014$ \\
\hline GPC2 & $04 / 06 / 2014$ \\
\hline GPC3 & $09 / 06 / 2014$ \\
\hline GPC4 & $11 / 06 / 2014$ \\
\hline GPC5 & $13 / 06 / 2014$ \\
\hline GPC6 & $09 / 07 / 2014$ \\
\hline GPC7 & $16 / 07 / 2014$ \\
\hline GPC8 & $06 / 08 / 2014$ \\
\hline GPC9 & $13 / 08 / 2014$ \\
\hline GPC10 & $18 / 08 / 2014$ \\
\hline GPC11 & $22 / 08 / 2014$ \\
\hline GPC12 & $26 / 08 / 2014$ \\
\hline \multicolumn{2}{|c|}{ Fonte: Arquivo da escola }
\end{tabular}

Em seguida, dei início ao processo de organização das fontes, a partir da leitura de todos os documentos digitalizados. Nessa etapa, selecionei os documentos que eram pertinentes para elucidação do objeto de estudo da tese, sobre os quais, fiz registro no "diário de pesquisa", com descrição sucinta do documento e indicação de sua localização nas pastas virtuais, dessa forma, foi possível classificar os documentos por tipos de fontes obtidas e por período compreendido. Os documentos selecionados foram classificados como "documentos relativos a dinâmica da instituição" e "documentos relativos a disciplina escolar matemática". Para esse artigo, fiz os registro e análise somente dos documentos relativos a disciplina escolar matemática, dessa forma, para cada fonte histórica conhecida, identifiquei o período histórico sobre o qual a fonte apresenta informações e o número de documentos relativos a disciplina matemática, conforme o quadro 2.

Quadro 2: Documentos relativos a disciplina escolar matemática encontrados nas fontes históricas referentes ao período de 1904 a 1930, no Gymnasio Paes de Carvalho.

\begin{tabular}{|c|c|c|}
\hline Fontes Históricas & Período histórico & $\begin{array}{c}\text { Número de } \\
\text { Documentos }\end{array}$ \\
\hline Livro de Ofícios Expedidos & 1904 a 1911 & 17 \\
\hline Livro de Registro Histórico dos Funcionários & 1917 a 1924 & 2 \\
\hline Livro de "Actas de Concursos de Professor" & 1921 a 1930 & 3 \\
\hline Livro de Ofícios Expedidos & 1922 a 1925 & 18 \\
\hline Livro de Termos de Afirmação & 1923 a 1924 & 2 \\
\hline Livro de Correspondências Recebidas & 1926 a 1929 & 4 \\
\hline \multicolumn{2}{|c|}{ Total } & $\mathbf{4 6}$ \\
\hline
\end{tabular}

Fonte: Arquivo da escola

O livro de ofícios expedidos é o livro que contém as cópias dos ofícios enviados pelo diretor da escola, todos os ofícios eram numerados e datados, alguns apresentam algumas correções de texto. No caso do livro que contém ofícios do período de 1904 a 1911, todos os ofícios são manuscritos, enquanto que o livro com ofícios emitidos no período de 1922 a 1925 são datilografados. Este último, contém os relatórios minuciosos sobre as atividades desenvolvidas no ginásio nos períodos de julho de 1921 a agosto de 1922, de julho de 1922 a agosto de 1923 e de julho de 1923 a agosto de 1924, que 
apresentam, por um lado, dados referentes a matrículas, professores e exames, por outro, conflitos, questões e reflexões acerca de regulamentos e decretos, principalmente, no que se refere ao status de ginásio equiparado.

O livro de registro histórico dos funcionários, que data de 1933, contém o registro de todos os funcionários da época, incluindo serventes, secretários, porteiros e professores. $\mathrm{O}$ registro continha o nome do funcionário, sua naturalidade, data de nascimento, nome dos pais e "signaes", tais como, cor, altura, cor dos olhos e cor dos cabelos. Além disso, continha todas as noemações recebidas pelo funcionário e, em alguns casos, foto. Este livro contém o registro históricos dos professores dr. Augusto de Oliveira Serra, lente catedrático de aritmética e álgebra e dr. João Dias da Silva, lente catedrático de matemática.

Figura 1 - Registro histórico do Dr. Augusto de Oliveira Serra

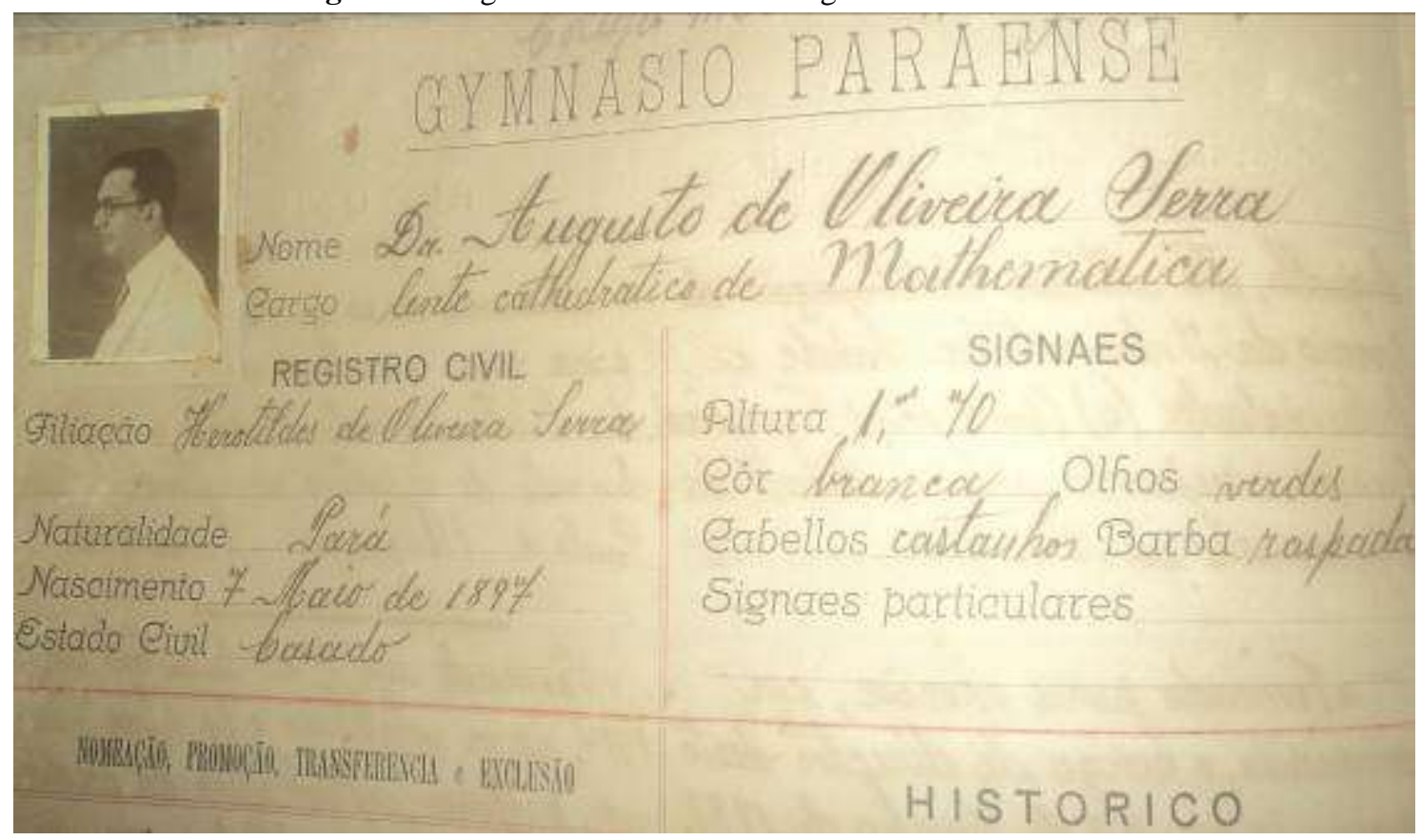

Fonte - Arquivo da Escola (2014)

O livro de atas de concurso do ginásio é uma fonte que nos permite compreender como eram selecionados os professores catedráticos do ginásio no período de 21 de janeiro de 1921 a 11 de janeiro de 1930. Esse livro contém a ata de concurso do candidato Augusto de Oliveira Serra, primeira ata do livro, para o provimento efetivo da cadeira de matemática, vaga com a aposentadoria do catedrático Ignacio Baptista de Moura. Além dessa ata, o livro contém as atas de concurso dos candidatos Antônio Travassos da Rosa e José de Castro Ribeiro, de 21 de outubro de 1921, e do candidato João Dias da Silva de 1925, ambos para o provimento efetivo da segunda cadeira de matemática vaga de Marcos Antônio Nunes. As atas de concurso também revelam o ritual do concurso, que compreendia a apresentação de trabalho original e inédito; arguição do candidato para verificar a autenticidade ou paternidade do trabalho; preleção de 40 minutos sobre um dos pontos do programa da cadeira, tirado a sorte 24 horas antes; resolução de questões relativas às partes constitutivas da cadeira. 
Figura 2 - Livro de "Actas de Concursos" de professor

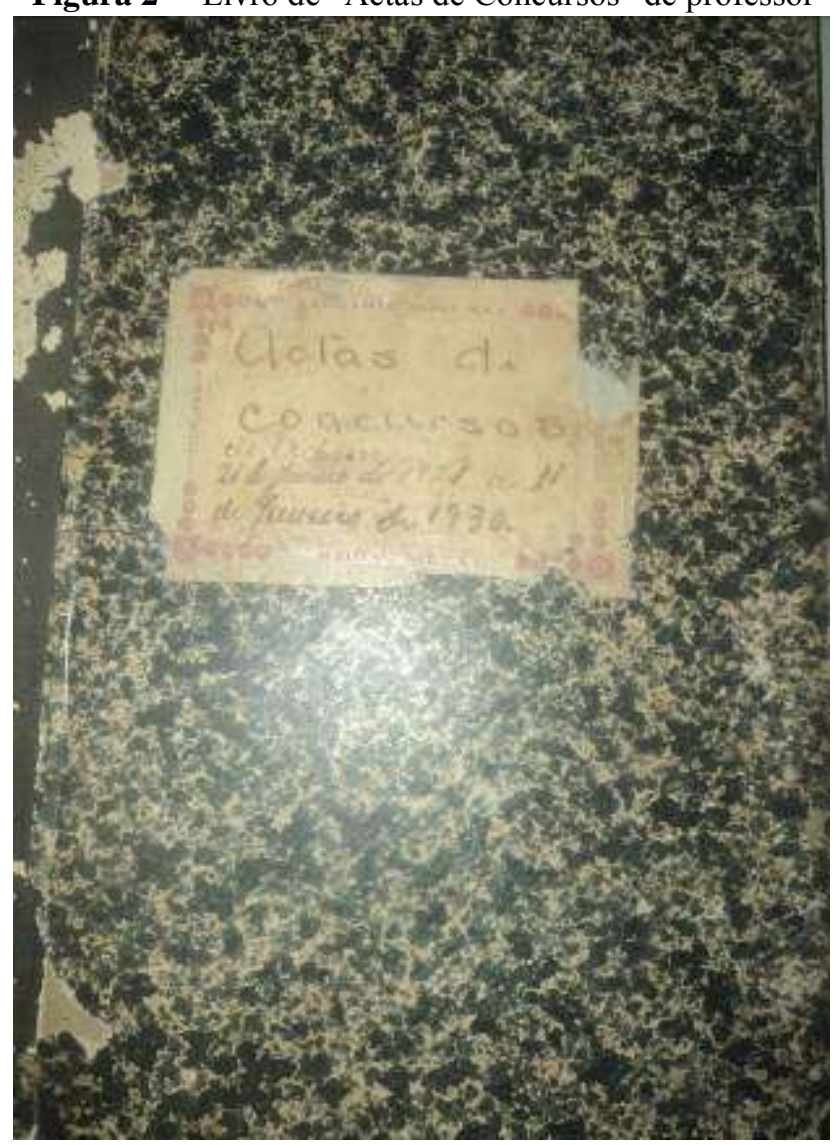

Fonte - Arquivo da Escola (2014)

O livro de termos de afirmação contém os termos de afirmação que prestavam os professores para exercer o cargo de professor do ginásio, cada termo relata o dia, local e professor nomeado, bem como, o tipo de cargo e cadeira que iria assumir. Nele podemos identificar que o professor, ao assumir um cargo, deveria prestar um juramento de bem servir os deveres que lhe eram impostos, cada termo era assinado pelo professor nomeado, pelo diretor do ginásio e pelo secretário. Os termos de afirmação referentes a matemática no livro são de José Balthasar de Oliveira Serra, professor auxiliar da cadeira de aritmética, nomeado em 11 de julho de 1923 e de Francisco da Silva Nunes, professor suplementar da cadeira de matemática, nomeado em 15 de abril de 1924. 
Figura 3 - Termo de afirmação do Prof. Francisco da Silva Nunes

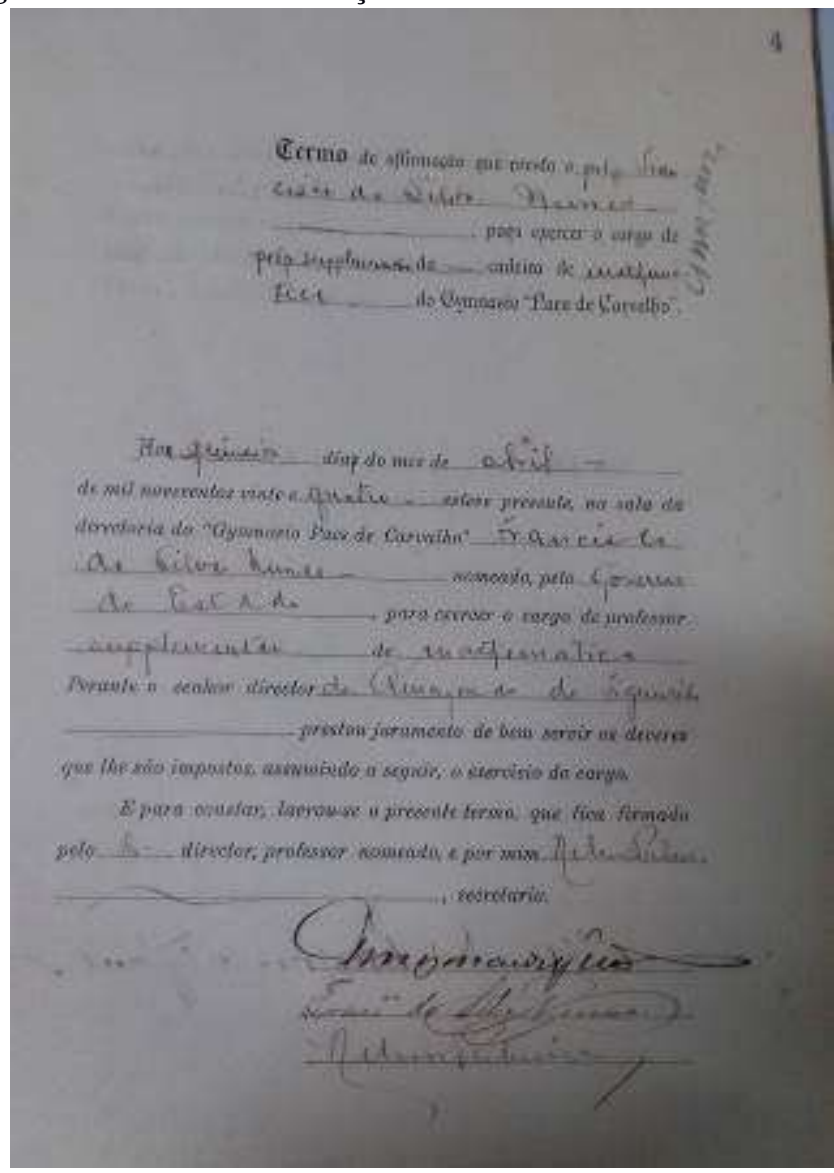

Fonte - Arquivo da Escola (2014)

O livro de correpondências recebidas é um livro que contém os ofícios recebidos pelo ginásio e que também revela muito das suas relações interinstitucionais, inclusive com instituições fora do Estado do Pará. Porém, nesse livro é possível identificar a forma como o Gymansio Paes de Carvalho era visto por essas outras instituições e revelam sua importância no cenário educaional nacional e internacional.

\section{As fontes históricas e a disciplina escolar matemática no Gymnasio Paes de Carvalho}

A análise das fontes históricas relativas a disciplina escolar matemática me permite fazer considerações acerca de algumas dimensões da matemática escolar, principalmente, no que se refere aos professores que ensinavam matemática no Gymansio Paes de Carvalho. É importante ressaltar que ser professor do ginásio era usufruir de status na sociedade paraense e que para compreendermos as transformações curriculares de uma disciplina escolar é necessário situar o conhecimento, a escola e os professores.

Não pretendo aqui fazer uma listagem de quem foi professor no ginásio, conforme a pesquisa de Gaspar, Borges e Chaquiam (2010), pois creio que as fontes históricas encontradas no arquivo da escola nos permitem ir para além do "quem", uma vez que nos possbilita desvelar um pouco da cotidianidade das relações interpessoais e interinstitucionais dos atores da escola.

Como exemplo, vou destacar o primeiro professor que identifiquei nas fontes 
históricas encontradas no arquivo da escola, que foi o engenheiro Ignacio Baptista de Moura, lente catedrático de aritmética e álgebra desde 1890. O primeiro registro que obtive desse professor data de 20 de abril de 1904, em um ofício destinado ao Secretário de Estado da Justiça, Interior e Instrucção Pública, com o requerimento de licença saúde de dois meses. O registro de retorno do professor da licença saúde data somente em agosto do mesmo ano, sem indicação de quem ficou no seu lugar por esse período. Já no ofício $\mathrm{n}^{\mathrm{o}}$. 136 de 17 de março de 1905, o professor encontar-se novamente licenciado, porém, desta vez, o dr. Eneias Calandrini Pinheiro, lente catedrático de macância, astronomia e topografia, o substitui. Em 7 de setembro de 1905, Ignacio Moura toma assento nos trabalhos do Congresso do Estado e deixa a cadeira que ocupava no ginásio, nomeia-se então o Dr. Philegnésio Augusto Penna de Carvalho como interino do dito lugar, porém, o mesmo não aceita e, novamente, designa-se Dr. Eneias Calandrini Pinheiro para substituir o catedrático. No ofício no 165 de 4 de outubro de 1905, o diretor comunica ao Secretário de Estado que o sr. Theodorico Napoleão da Costa e Silva, recentemente nomeado para a cadeira de artimética e álgebra, também não aceitou o lugar.

O lente Ignacio Moura, junto com o tenente coronel Sabino Henrique da Luz, lente de geometria e trigonometria desde 1895, ministrava a disciplina escolar matemática no ginásio. Nesse período, a matéria matemática era dividida em duas cadeiras, a primeira composta por Aritmética e Álgebra e a segunda por Geometria e Trigonometria. Dos seis professores catedráticos do ginásio, dois eram ligados a matemática, o que era uma forte representação política da área na instituição, já que cabia somente aos lentes e professores catedráticos participar nas sessões solenes e reuniões da congregação, cabendo aos lentes e professores interinos tomarem parte somente quando se tratassem de assuntos relativos as cadeiras que estivessem regendo. Além disso, o tenente coronel, que em 1906 se tornou major, ocupou o cargo de vice-diretor do ginásio e se tornou Intendente de Belém, conforme ofício $\mathrm{n}^{\circ}$. 205, expedido em 12 de setembro de 1906.

De acordo com Gapar, Borges e Chaquiam (2010, p. 158)

O engenheiro Joaquim Gonçalves foi nomeado como professor interino de matemática em 23 de abril de 1901 para a cadeira de Geometria e Trigonometria, tomando posse dois dias depois. Também foi nomeado pra a mesma cadeira o professor interino Claudemiro Julio de Andrade Figueira em 28 de agosto de 1901.

Para a cadeira de Aritmética e Álgebra foi nomeado como professor interino Horácio Henrique da Silva em 09 de maio de 1902 tomando posse três dias depois. No dia 30 de abril de 1904 era nomeado como professor interino, para a mesma cadeira, o Dr. Philegnésio Augusto Penna de Carvalho, vindo tomar posse em quatro de maio do mesmo ano. O Dr. Eustáchio F. Da Costa Rodrigues foi nomeado no dia 05 de agosto de 1912 como professor efetivo da cadeira de Aritmética e Álgebra, tomando posse em 08 de agosto do referido ano.

Embora os autores afirmem ter obtido essas informações no arquivo da escola, dentre as fontes pesquisadas, somente encontrei registro do Dr. Philegnésio Augusto Penna de Carvalho, que em 1905 rejeitou a nomeação de professor interino para a cadeira ocupada por Ignacio Moura. Além disso, até 1909 não existia lente interino de matemática, cabendo aos lentes, catedráticos ou interinos, de outras cadeiras assumirem as cadeiras de matemática quando necessário, como é o caso de Antônio Travassos da Rosa, lente de mecânica e astronomia, que assumiu a cadeira de Ignacio Moura, conforme o ofício $\mathrm{n}^{\mathbf{0}} .39$ expedido em 9 de setembro de 1910. 
O lente Antônio Travassos da Rosa é um personagem que merece atenção em análises futuras sobre a história da matemática escolar no ginásio, uma vez que sobre sua vida no ginásio há o registro de sua nomeação como professor interino de primeira cadeira de matemática, a ata de concurso que realizou para a cadeira de catedrático e a tese defendida por ocasião do concurso no qual não foi aprovado. Dessa forma, é possível descrever uma trajetória desse professor no ginásio e sua relação com a matemática. Na ata de concurso de Augusto de Oliveira Serra consta que a banca era composta, dentre outros, por Antônio Travassos da Rosa, lente interino de francês. Ou seja, Antônio Travassos da Rosa, lente de mecânica e astronomia, assumiu interinamente a primeira cadeira de matemática e também a cadeira de francês, e ainda participou de banca de concurso do candidato a vaga que ocupou interinamente.

\section{Considerações Finais}

As idas e vindas de ofícios são registros de pequenas histórias do cotidiano escolar, de formas de tratamento entre atores institucionais e pessoais, de eventos importantes e de debates sobre questões relativas ao currículo e alunos. As fontes históricas analisadas até o momento, contribuem para situar o ensino da matemática no contexto curricular da escola, porém, ainda não revelam o ensino efetivado dessa disciplina. Devido ao processo de equiparação do ginásio ao Ginásio Nacional, torna-se necessário o estudo de fontes externas a escola de modo a analisar as transformações curriculares ocorridas a nível nacional e também internacional, tais como, programas de ensino do ginásio da corte, livros didáticos adotados na época, leis, decretos e regulamentos.

Quanto aos professores que ensinavam matemáticas nessas instituição, para além da cotidianidade revelada, é necessário a busca pela sua formação em fontes externas, de modo a traçar-lhes um perfil, já que nesse período não havia os cursos de licenciatura nessa área de conhecimento. Mas, é a partir das fontes históricas do arquivo da escola que podemos refletir se esses professores eram protótipos ou arquétipos dos atuais professores de matemática.

Considero que, embora essas fontes ainda sejam insuficientes para apresentar uma história da matemática escolar no Gymansio Paes de Carvalho, no período de 1889 a 1930 , sem elas, tampouco, conseguiríamos fazer a escrita dessa história. Essas fontes, mais do que "elo perdido" entre o que era prescrito em âmbito nacional e o ensino efeitvado, nos ajudam a lançar novos olhares sobre o currículo, os professores e a constituição da disciplina escolar matemática, bem como, escrever parte da história dessa instituição de ensino.

\section{Referências}

ABUD, Katia M. A história e o ensino temático. Anais do XVII Simpósio Nacional de História - ANPUH, São Paulo, julho 1993, p. 492-501.

APPLE, Michael N. Ideologia e currículo. $2^{\circ}$ ed. Porto Editora, 1999.

BASSALO, José M. F. O ensino da Física em Belém do Pará. Revista Brasileira de Ensino de Física, vol 17, nº 2, junho/1995, p. 152-158. 
CHAQUIAM, Miguel; GASPAR, Elaine da S.; BORGES, Gleeydson F. L. História da Educação no Pará: do Liceu Paraense ao Paes de Carvalho. In: Encontro Paraense de Educação Matemática, Belém, 2010, p. 1-11.

CHERVEL, André. História das Disciplinas Escolares: reflexões sobre um campo de pesquisa. Revista Teoria e Educação, Porto Alegre, vol.2, 1990. p. 177-229.

FRANÇA, Maria do P. S. De S. A. de. Raízes históricas do ensino secundário público na Província do Grão Pará: o Liceu Paraense. Universidade Estadual de Campinas, Faculdade de Educação, Campinas, SP, 1997 (Dissertação de mestrado).

GASPAR, Elaine S.; BORGES, Gleeydson F. L.; CHAQUIAM, Miguel. Liceu Paraense: berço cultural na Amazônia. Revista Traços, Belém, vol. 12, n. 25, jun. 2010, p. 149-169.

GRACEZ, Angelina N. R. Fontes complementares na pesquisa historiográfica. In: CASIMIRO, Ana P. B. S.; LOMBARDI, José C.; MAGALHÃES, Lívia D. R. (org.) A pesquisa e a preservação de arquivos e fontes para a educação, cultura e memória. Campinas, SP: Editora Alínea, 2009.

GOODSON, Ivor. O currículo em mudança: estudos na construção social do currículo. Porto: Porto Editora, 2001.

LE GOFF, Jaques. História e memória. 2. Vol. Lisboa: Edições 70, 2000.

LOMBARDI, José C.. História e historiografia da educação: atentando para as fontes. In: LOMBARDI, José C.; NASCIMENTO, Maria. I. M. (org.) Fontes, história e historiografia da educação. Campinas, SP: Autores Associados: HISTEDBR; Curitiba, PR: Pontifícia Universidade Católica do Paraná; Palmas, PR: Centro Universitário Diocesano do Sudoeste do Paraná (UNICS); Ponta Grossa, PR: Universidade Estadual de Ponta Grossa (UEPG), 2004. - (Coleção Memória da Educação)

LOPES, Alice R. C. História do currículo na pós-graduação em educação da UFRJ (19721981): concepções de conhecimento e pesquisa. Revista Brasileira de Educação, $\mathrm{n}^{\circ} 7$, 1998, p. 57-73.

MIGUEL, Maria E. B. Do levantamento de fontes à construção da historiografia: uma tentativa de sistematização. In: LOMBARDI, José. C.; NASCIMENTO, Maria. I. M. (org.) Fontes, história e historiografia da educação. Campinas, SP: Autores Associados: HISTEDBR; Curitiba, PR: Pontifícia Universidade Católica do Paraná; Palmas, PR: Centro Universitário Diocesano do Sudoeste do Paraná (UNICS); Ponta Grossa, PR: Universidade Estadual de Ponta Grossa (UEPG), 2004. - (Coleção Memória da Educação)

NUNES, Antonietta D.; MATOS, Maria T. N. de B.; CABRAL, Ilma da S. Os arquivos e a memória da educação na Bahia: recordando localmente para conhecer globalmente. In: CASIMIRO, Ana P. B. S.; LOMBARDI, José C.; MAGALHÃES, Lívia D. R. (org.). A pesquisa e a preservação de arquivos e fontes para a educação, cultura e memória. Campinas, SP: Editora Alínea, 2009.

PACHECO, José A. Educação, formação e conhecimento. Porto: Porto Editora, 2014.

RÊGO, Clóvis S. de M. 1925 - Subsídios para a história do Colégio Estadual "Paes de Carvalho". Belém: EDUFPA / L\&A Editora, 2002.

RIBEIRO, Joyce O. S. A tradução da tradição em práticas curriculares no Colégio Estadual Paes de Carvalho. Universidade Federal do Pará, Instituto de Ciências da Educação, Programa de Pós-graduação em Educação, Belém, 2013 (Tese de doutorado). 
ROCHA, Genylton O. R. da. A trajetória da disciplina geografia no currículo escolar brasileiro (1837-1942). Pontifício Universidade Católica de São Paulo, Programa de Pósgraudção em Supervisão e Currículo, São Paulo, 1994 (Dissertação de mestrado).

SAVIANI, Dermeval. Breves considerações sobre fontes para a história da educação. In: LOMBARDI, José. C.; NASCIMENTO, Maria. I. M. (org.) Fontes, história e historiografia da educação. Campinas, SP: Autores Associados: HISTEDBR; Curitiba, PR: Pontifícia Universidade Católica do Paraná; Palmas, PR: Centro Universitário Diocesano do Sudoeste do Paraná (UNICS); Ponta Grossa, PR: Universidade Estadual de Ponta Grossa (UEPG), 2004. - (Coleção Memória da Educação)

SILVA, José C. de A. Fontes documentais para o estudo do cotidiano das escolas pelo método de ensino mútuo por meio da "Série Colonial" do Arquivo Público do Estado da Bahia. In: CASIMIRO, Ana P. B. S.; LOMBARDI, José C.; MAGALHÃES, Lívia D. R. (org.) A pesquisa e a preservação de arquivos e fontes para a educação, cultura e memória. Campinas, SP: Editora Alínea, 2009.

SILVA, Tomaz T. da. Apresentação. In: Goodson, Ivor. Currículo: teoria e história. Petrópolis, RJ: Editora Vozes, 2013.

TOLEDO, César de A. A.; GIMENEZ, José C. Educação e pesquisa: fontes e documentos. In: CASIMIRO, Ana P. B. S.; LOMBARDI, José C.; MAGALHÃES, Lívia D. R. (org.) A pesquisa e a preservação de arquivos e fontes para a educação, cultura e memória. Campinas, SP: Editora Alínea, 2009.

VALENTE, Wagner. R. Mello e Souza e a crítica aos livros didáticos de matemática: demolindo correntes, construindo Malba Tahan. Revista Brasileira de História da Matemática, vol. 4, no 8, 2004, p. 171-187.

\footnotetext{
${ }^{1}$ Bolsista do Programa de Doutorado Sanduíche no Exterior - PDSE/CAPES
}

Recebido: mai/15 Aprovado: jun/15 